\title{
Investigation of Astrocyte Cell Growth on Metal, Semi-Conductor and Insulator Surfaces
}

\author{
A. Maydanov*, A. Calabro*, C. Queenan*, D. Becker*, and D. Kim* \\ * Bergen County Academies, 200 Hackensack Avenue, Hackensack, NJ 07601
}

Cell adhesion is a fundamental biological step that can determine overall growth of its cell. The extracellular matrices at the cell-surface interface are known to affect cell adhesion and eventually control growth and differentiation of animal cells [1].Correlation between the cell adhesion and the cell growth is significant in the field of biomedical engineering such as tissue engineering, biosensor development, and etc. In this study, metal, semi-conductive and insulator surfaces are chosen to study their impact on the neuronal cell growth and adhesion. Biosensors can non-invasively record the activity of an antibody, enzyme, or cell by picking up electrical signals from them. Data collection and accuracy can be dramatically improved if there's no gap at the interface of its host cell and sensory device [2].

Neuronal mouse astrocyte cells (ATCC, CRL-2541) were cultured on platinum (Pt), gold (Au), silicon $(\mathrm{Si})$, and silicon dioxide $\left(\mathrm{SiO}_{2}\right)$ surfaces for 24 hours. Surfaces were sterilized with methanol and ultraviolet light before culture. No protein coating was applied on these surfaces. For scanning electron microcopy (SEM; FEI Quanta 200 3D), the samples were fixed with 5\% glutaraldehyde in phosphate buffered saline, dehydrated in a gradient series of ethanol, critical point dried, and coated with a thin conductive carbon layer. ImageJ particle analysis of the images showed the total number of cell count and coverage on each surface. Transmission electron microcopy (TEM; JEOL JEM2100) was used to investigate the distance between the cell and the substrate. Additional set of samples were fixed with $4 \%$ glutaraldehyde/ $2 \%$ formaldehyde in $0.2 \mathrm{M}$ sodium cacodylate buffer, post-fixed with $2 \%$ osmium tetroxide, dehydrated in a gradient series of acetone, infiltrated with a progression of Spurr's epoxy resins, placed upside down in a Chang monolayer embedding mold filled with fresh resin and incubated at $60^{\circ} \mathrm{C}$ for two days. After resin curing, the substrates were removed by liquid nitrogen freeze fracture and ultrasonication. Before re-embedding the samples with resins, the interface was marked with a thin layer of gold. After sectioning with Leica EMUC6 Ultramicrotome, samples were stained with $4.0 \%$ uranyl acetate for two hours and $0.5 \%$ lead citrate for 30 minutes on grids.

SEM micrographs of astrocyte cells grown on different surfaces were depicted in Figure 1. Cells grew and covered $\mathrm{Si}$ (total cell coverage $28 \%$ ), Pt (21\%) and $\mathrm{SiO}_{2}(18 \%)$. Cells were not prolific on $\mathrm{Au}$ and showed a mere $3 \%$. It is also noted that only circular shaped cells were present on gold surface (Figure 1E). Detailed image analysis revealed the existence of circular shaped cells on all the surfaces. Interestingly, metal surfaces contained similar ratio of total number of circular cells to linear shaped cells (Pt: 0.32 and $\mathrm{Au}$ : 0.37) while silicon and silicon dioxide showed same (Si: 0.20 and $\mathrm{SiO}_{2}: 0.16$ ). It is hypothesized that cells were not able to spread out on the Au surface due to poor adhesion. However, TEM micrographs on gold surface (Figure 2B \& C) showed no gap between cells and gold surfaces while linear shaped cells on silicon dioxide showed many large gaps (Figure 2A). So far, these results suggest silicon as a good candidate semi-conductive surface and platinum as a good metal candidate surface for astrocyte cells. Further studies will be conducted to improve the interface adhesion of linear shaped cells. 


\section{References}

[1] L. Bacakova et al., Physiological Research (2004) 53 35-45.

[2] G. Wrobel et al., Journal of the Royal Society Interface (2007) 5 213-22.

[3] The authors would like to acknowledge Ms. Donna Leonardi for her assistance with cell culture and the administration of the Bergen County Technical Schools District for their continued support. Partial funding for this research was provided from Young Science Achievers Program.
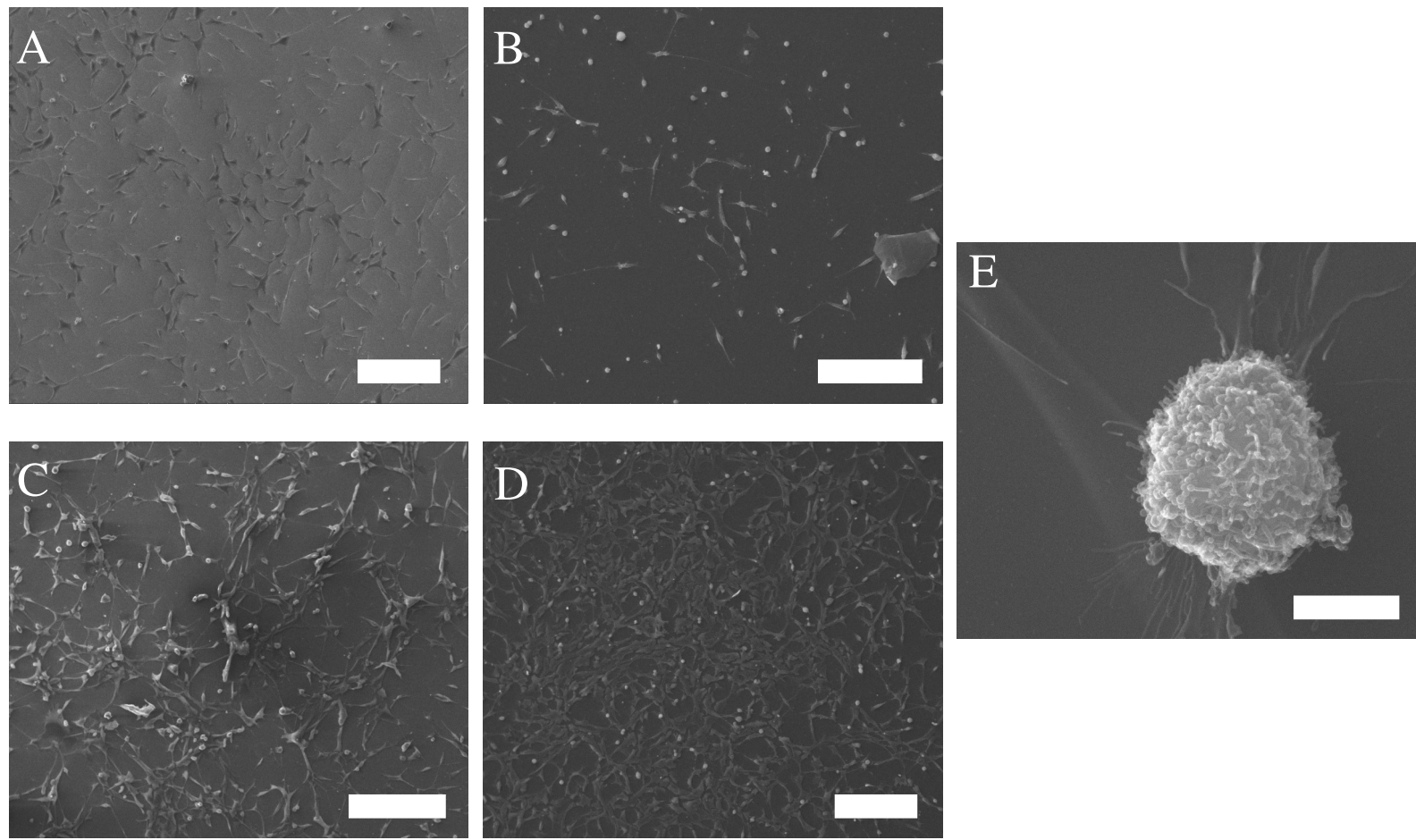

Figure 1: SEM images of astrocyte cells grown on (A) Pt (B) $\mathrm{Au}$ (C) $\mathrm{SiO}_{2}$ (D) Si, scale bar $200 \mu \mathrm{m}$ for A-D; (E) a circular shaped cell on $\mathrm{Au}$, scale bar $4 \mu \mathrm{m}$. Total cell count, highest to lowest: $\mathrm{Si}$, $\mathrm{SiO}_{2}, \mathrm{Pt}$, and $\mathrm{Au}$. Total cell coverage, $\mathrm{Si}, \mathrm{Pt}, \mathrm{SiO}_{2}$ and $\mathrm{Au}$.
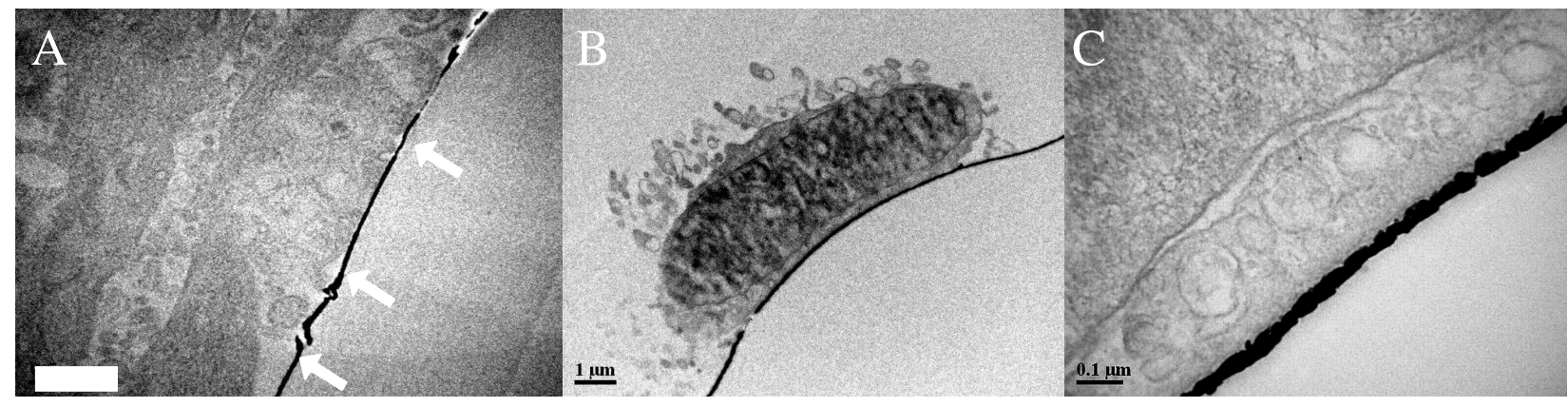

Figure 2: TEM images of cross-sections of astrocyte cells grown on (A) $\mathrm{SiO}_{2}$, scale bar $0.5 \mu \mathrm{m}$, (B) on $\mathrm{Au}$ and $(\mathrm{C})$ close-up on $\mathrm{Au}$. Dark line is the gold layer marking the interface between the substrate and the cell. Note close adhesion on $\mathrm{Au}$ and many gaps on $\mathrm{SiO}_{2}$ marked by arrows. 